\section{Lunar Tide in the Atmosphere}

THE Meteorological Magazine of December 1939 contains a summary by Prof. S. Chapman of his presidential address to the Association for Meteorology at the Washington Assembly of the International Union for Geodesy and Geophysics last September, the subject being the lunar tide in the atmosphere. The author describes the difficulty that was met when the detection of this lunar tide, achieved first by Lefroy in 1842 for St. Helena, was attempted for higher latitudes, which resulted in a succession of failures that was not broken until his own determination in 1918 of the very small Greenwich air tide, from sixty-four years of hourly data. From that year, when the tide was known for three tropical stations and one non-tropical, progress was rapid, and the rate of determination by Prof. Chapman and his assistants was increased threefold in 1930 through a loan of Hollerith machines by the British Tabulating Machine Co. Now the tide has been determined for more than fifty places.

With this number of determinations available for study of the world distribution of phase and amplitude, several interesting peculiarities have come to light; for example, an early maximum is shown at Salt Lake City, San Diego and San Francisco, this being two hours before the upper and lower lunar transits at the last two places, but at the neighbouring high-level stations of Mount Wilson Observatory and Mount Hamilton (Lick) the tide, although similarly small for the latitude, has roughly the normal phase with high tide after the moon's transits, an effect doubtless due to the presence of the great mountain chain of North and South America. Similar effects are, however, not shown by Kodaikanal and Periyakulam, in India, although the heights of those places differ more than do those of the American stations, the differences being as much as 2,249 metres. Equally remarkable is the practically world-wide retardation of the time of high tide in Lecember and January as compared with April or May, in spite of the fact that summer in one hemisphere corresponds with winter in the other. Work has been begun on the determination of the air currents of period equal to half a lunar day that must be associated with the pressure tide; this problem is being attacked with the aid of the long record available at Batavia.

\section{Ultra-Violet and Infra-Red Radiations on the Farm}

L. C. Porter, of the General Electric Company's incandescent lamp department in Cleveland, said, at a meeting of the American Society of Agricultural Engineers held on December 7, that if only electric current becomes cheap enough and suitable equipment is developed, then ultra-violet and infra-red radiations can have many uses on the electrified farm of the future (Science Service, Washington, D.C.). Adaptations of the familiar dull-red glowing electric heaters can readily be made for use in poultryhouses, in barns to keep new-born animals warm, and for the quick drying of hay. The greater com- pactness and decreased fire risk will give them considerable advantage over present types of equipment. Ultra-violet rays are known to have certain wellmarked physiological effects, as in activating sterols to produce vitamin $\mathrm{D}$ and in keeping in check the growth in length of plants. For producing wellproportioned plants in greenhouses, the use of a new kind of incandescent lamp is suggested which has a globe permeable to ultra-violet as well as to visible rays.

- With these and other lamps in proper proportions, a close approximation to natural sunlight can be obtained with control of duration and intensity not possible under natural conditions. The well-known germicidal effects of ultra-violet rays still await a number of possible practical applications on the farm. They may be used, for example, in dairies and stable buildings, as they now are in hospitals to keep down the germ population of the air. They may be called on to control the spread of epidemics among farm animals, and to check the growth of moulds and other fungi on hay, grain and other products. Their fluorescent effects may aid in diagnosing animal diseases and in examining vegetables and fruits. With Dr. Buttolph, physicist of the General Electric Company, Mr. Porter is publishing some of his suggestions in Agricultural Engineering.

\section{Helium Production in the United States}

THE developments of the last twenty years in helium production in the United States are described in Engineering of January 26. Reference is made to a lecture delivered recently in the College of Engineering of the University of Maryland by Dr. C. W. Siebel, supervising engineer of the Government-owned helium plant near Amarillo, Texas, and to a memorandum issued by the United States Bureau of Mines. The present helium-producing plant at Amarillo has a capacity of 24 million cubic feet of helium of 98.2 per cent purity a year, but it is stated in the Bureau of Mines memorandum that, by installing another production unit in existing buildings, the output could be raised to 36 million cubic feet a year. As the present military and commercial requirements, aggregating approximately 6 million cubic ft. a year, are met by operating the plant at about one quarter of the installed capacity, there is a large reserve for emergencies.

In addition to the Amarillo installation, the U.S. Government owns two smaller helium plants, at Dexter, Kansas, and at Thatcher, Colorado ; these are not being worked. They were built by private interests and purchased by the Government in 1937. To supply the Armarillo plant with helium-bearing natural gas, the Bureau of Mines has purchased all gas rights in 50,000 acres of land comprising the Cliffside gas field. It is stated that, on the basis of a conservative estimate, the Cliffside area contains at least 100,000 million cubic feet of natural gas having a helium content of 1.8 per cent. This is equivalent to a reserve of 1,800 million cubic feet of helium, or approximately two hundred times the 
average annual production during the last ten years. In addition to the resources at Cliffside, the U.S. Government possesses two helium reserves in Utah, which are being retained for future needs.

\section{Mineral Resources of the British Empire}

DurING the War of 1914-18 a Royal Commission formed the conclusion that an Empire Development Board was desirable, and there the project has been allowed to rest. An editorial article in Sands, Clays and Minerals (autumn issue, 1939) urges that no time should be lost in an intensive survey of the mineral resources of the Empire. The War, so far from causing a postponement of such a survey, should hasten it, and the survey must be carried out from a national point of view regardless of the possible financial profit that may accrue from the mining of any mineral. We cannot afford to wait while commercial interests debate the potential profit in a new venture: access to new supplies of a mineral ore may be vital to victory. The writer makes it clear that he is not thinking in terms of politicians and their methods of control. In that direction he foresees no hope of initiative. If anything is to be done, technologists will have to get together and do it for themselves.

It is proposed that the scientific men of Great Britain should draw up a scheme of Empire development, communicate it to corresponding groups in the Dominions and Colonies, and then give the plan such publicity that even the dead hand of the politician could not destroy it, and possibly some public-spirited men might launch the venture free from the shackles of official control. Emphasis is laid on the conception of a just minerals policy for the Empire in the peace that is to come, the necessity for preventing the exploitation of resources falling to the wrong kind of private enterprise in which profits are the one consideration, and finally the desirability of making the Empire's mineral resources available to all.

\section{An Artificial Mastoid for Audiphone Measurements}

THe Bell Laboratories Record of November 1939 contains a paper on the development of boneconduction audiphone receivers by M. S. Hawley, of the Transmission Instruments Engineering Department of the Laboratories. To provide a method of measuring the response of bone conduction receivers under the correct mastoid load, an artificial mastoid was developed. The impedance offered by the mastoid to a bone conduction receiver was measured on a number of people and then a rubber block was designed that presented to a receiver placed upon it approximately the same impedance as the average human mastoid. Since the artificial mastoid is based on average values of mastoid impedance, there may be slight variations in the results obtained with it and with some particular subject. The possible deviations are indicated by a diagram, which shows responses obtained with the artificial mastoid and with one particular subject. At very low frequencies here is an evident slight departure, but over the major part of the frequency range the results are in close agreement. Measurements on the same instruments made over a period of a year have shown very good correlation. Eventually the rubber pad ages and its impedance changes. The replacement of the old pad by a new one is a simple matter, so that the ageing of the rubber pad is not of much consequence. The artificial mastoid may be used in making other tests on receivers in which it is desired that the receiver be coupled to an impedance load equal to that of the head. Such tests include electrical impedance measurements, rattle tests, and nonlinear distortion measurements.

\section{Earth Tremor in New Jersey}

The United States Coast and Geodetic Survey, in co-operation with Science Service and the Jesuit Seismological Association, has now determined the epicentre of the earthquake of November 14, 1939, to have been near lat. $39^{\circ} 45^{\prime} \mathrm{N}$., long. $75^{\circ} 18^{\prime} \mathrm{W}$., which is only $10^{\prime}$ due south of the point suggested as being very near to the epicentre by the Franklin Institute at Philadelphia. The depth of focus is estimated as having been about $25 \mathrm{~km}$.

We are indebted to Prof. William A. Lynch, of Fordham University, New York, for the information that in the summer of 1938 a series of local shocks occurred to the north-east of the above epicentre in the region of lat. $40^{\circ} 8 \cdot \mathrm{N}$., long. $74^{\circ} 32^{\prime} \mathrm{W}$., the two most severe of which were on August 23 at $3 \mathrm{~h} .36 \mathrm{~m}$. and $7 \mathrm{~h} .3 \mathrm{~m}$. G.M.T. On the basis of a canvass of volunteer correspondents and observers, the Coast and Geodetic Survey then announced that the intensity of these "apparently did not exceed V according to the Modified Mercalli Scale of 1931" (felt by nearly everyone; many awakened; some dishes, windows, etc., broken; a few instances of cracked plaster, etc.). The earth tremor was not strong enough to be registered on the seismographs at Kew Observatory. "Earthquake History of the United States", part I (1938), published by the Survey, lists only four moderately strong earthquakes for New Jersey up to the year 1936. In our previous note on the earthquake (NATURE, Nov. 25, 1939 , p. 904) New Jersey was wrongly stated to be one of the New England States.

\section{Central European Observer}

WHEN the Czech nation lost its independence in 1620 its cultural life ceased. Yet Comenius and other teachers continued their educational work in exile. To-day, the nation is again under foreign domination, its universities and scientific institutions are closed and its cultural publications no longer appear in the country itself. One has, however, restamed publication in London. From 1923 until the end of 1938, there appeared in Prague the Central European Observer, a review in English dealing with science, art, literature and industry and with European affairs generally. In common with other Czech cultural reviews, it suspended publication after the virtual loss of independence in 1938. It is now appearing again as a fortnightly journal "to study, as it had done 